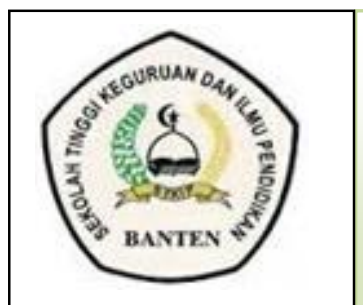

Sportif 6 (1) (2021): 28-34
SPORTIF

JURNAL PENDIDIKAN JASMANI, KESEHATAN DAN REKREASI

http://journal.pjkr.ac.id/sportif

\title{
PENGARUH LATIHAN BEBAN TERHADAP PUKULAN SMASH PADA PERMAINAN BOLA VOLI
}

\author{
Ahmad Yanuar Syauki \\ Program Studi Pendidikan Jasmani Kesehatan dan Rekreasi \\ Sekolah Tinggi Keguruan dan Ilmu Pendidikan Banten \\ Penulis Korespondensi : aysyauki@yahoo.com
}

Artikel: Pukulan Smash Permainan Bola Voli

Penerima: Januari, 2021

Diterima: Februari, 2021

Dipublikasikan: Maret, 2021

\begin{abstract}
ABSTRAK
Berdasarkan hasil praobservasi masih menemukan beberapa permasalahan dalam permainan bola voli pada siswa. Permasalahan tersebut diantaranya : 1) masih banyak siswa yang mengalami kesulitan dalam melakukan keterampilan smash. Hal ini dikarenakan bola yang digunakan bola voli standar, sehingga hasil kurang maksimal. Bola dianggap besar, berat, keras dan sering mengalami sakit pada tangan. 2) Sebesar $68 \%$ siswa belum memenuhi KKM pada materi keterampilan smash dalam permainan bola voli. 3) Adanya keterbatasan sarana dan prasarana dalam permainan bola voli seperti alat permainan bola voli yang minim secara kuantitas dan kurang secara kualitas. Adapun tujuan dari penelitian ini adalah sebagai berikut : Melaksanakan dan mengetahui studi pendahuluan yang dilakukan untuk mengidetifikasi apakah latihan beban berpengaruh terhadap pukulan smash pada permainan bola voli. Jenis penelitian yang digunakan yaitu Studi Literatur yang merupakan penelitian mengumpulkan sejumlah buku buku, majalah yang berkaitan dengan masalah dan tujuan penelitian. Teknik ini dilakukan dengan tujuan untuk mengungkapkan berbagai teori-teori yang relevan dengan permasalahan yang sedang dihadapi/diteliti sebagai bahan rujukan dalam pembahasan hasil penelitian. Dapat disimpulkan bahwa latihan beban terhadap ketepan pukulan smash pada permainan bola voli sebelum dan sesudah pelaksanaan pukulan smash bola voli dengan menggunakan metode latihan beban berpengaruh secara signifikan terhadap ketepatan pukulan smash pada permainan bola voli.
\end{abstract}

Kata Kunci : latihan beban, pukulan smash, bola voli. 


\section{PENDAHULUAN}

Pendidikan merupakan kebutuhan sepanjang hayat. Setiap manusia membutuhkan pendidikan, sampai kapan pun dan di manapun ia berada. Pendidikan sangat penting artinya, sebab tanpa pendidikan manusia akan sulit berkembang dan bahkan akan terbelakang. Dengan demikian pendidikan harus betul-betul diarahkan untuk menghasilkan manusia yang berkualitas dan mampu bersaing, di samping memiliki budi perkerti yang luhur dan moral yang baik. Ilham Surya Fallo ${ }^{1}$.

Pendidikan jasmani merupakan salah satu dari mata pelajaran yang diberikan di Sekolah Menengah. Pendidikan jasmani pada siswa SMP menjadi sangat penting karena siswa berada pada masa perkembangan dan pertumbuhan. Hal ini menjadikan pendidikan jasmani di SMP lebih banyak ditekankan pada proses penguasaan keterampilan gerak melalui olahraga permainan. Permainan tersebut terdiri dari permainan individu dan permainan beregu. Pembelajaran pendidikan jasmani yang mengutamakan permainan beregu diantaranya adalah permainan bolavoli.

Proses belajar mengajar pendidikan jasmani, perlu mengetahui bagaimana sebenarnya pembelajaran itu berlangsung dan seorang guru dituntut untu kmengetahui pengetahuan, keterampilan dan sikap yang professional dalam membelajar kansiswa. Dalam pembelajaran keberhasilan siswa tidak hanya ditentukan oleh hasil pembelajarannya akan tetapi juga di pengaruhi oleh proses belajar mengajarnya, apa bila dalam pembelajaran, proses pembelajaran baik maka pencapaian hasil yang di harapkan akan tercapai, makadari itu guru harus benar-benar mempersiapkan materi yang akan diajarkan sebelum melakukan

\footnotetext{
${ }^{1}$ Ilham Surya Fallo (2016). upaya meningkatkan keterampilan smash permainan bola voli melalui pembelajaran gaya komando. Jurnal Pendidikan Olahraga. h.11

(C) 2021, Jurnal Sportif. PJKR

e-ISSN: 2775-9873
}

pembelajaran agar dapat melaksan akan tugas profesinya dengan baik.

Keberhasilan proses kegiatan belajar mengajar pada pembelajaran penjas dapat diukur dari keberhasilan siswa yang mengikuti kegiatan pembelajaran. Keberhasilan itu dapat dilihat dari tingkat pemahaman, penguasaan materi dan hasil belajar siswa. Semakin tinggi pemahaman, penguasaan materi dan hasil belajar maka semakin tinggi pula tingkat keberhasilan pembelajaran.

Permainan bola voli merupakan permainan beregu diatas lapangan berukuran panjang $18 \mathrm{~m}$ dan lebar $9 \mathrm{~m}$ yang membelah lapangan 2 sama besar. Lurus diatasnya terdapat net, dengan tinggi 2,43 $\mathrm{m}$ dan 2,24 $\mathrm{m}$. Terdapat 2 regu yang saling berhadapan dan setiap regu terdapat 6 pemain, 3 pemain sebagai penyerang dan 3 lainya bertahan. Viera, Permainan bola voli maksimal berlangsung selama 5 set. Pada set I sampai dengan set IV Bagi tim yang mengumpulkan poin 25 terlebih dahulu dengan minimal selisih 2 poin maka dinyatakan memenangkan set tersebut. Sedangkan pada set V tim dinyaktakan menang bila telah mengumpulkan 15 poin terlebih dahulu dengan minimal selisih 2 poin, satu regu dinyatakan memengangkan pertandingan bil telah memengakan sebanyak 3 set terlebih dahulu. Setiap regu mendaptakan poin bila mampu memenagkan reli, baik melakuakn servis maupun tidak ( FIVB).

Ilham Surya Fallo menyatakan dalam permainan bola voli terdapat 5 teknik dasar yang harus di kuasai meliputi, servis, passing, umpan (set-up), smash (spike), bendungan (block). Smash merupakan perpaduan gerakan yang tidak dapat dipisahkan. Kerjasama antar otot antara lain otot lengan, otot perut, otot tungkai, otot pinggul, otot bahu, dan kelentukkan togok sangat mempengaruhi keberhasilan dalam melakukan smash ${ }^{2}$.

\footnotetext{
${ }^{2}$ Ilham Surya Fallo (2016). upaya meningkatkan keterampilan smash permainan bola voli melalui pembelajaran gaya komando. Jurnal Pendidikan Olahraga. h.11
}

PJKR JURNAL 
Perkembangan bola voli meningkakan secara signifikan hal itu terlihat dengan banyaknya siswa berprestasi dalam cabang olahraga bola voli ini. Dalam permainan bola voli untuk mendapatkan prestasi yang gemilang, maka perlu adanya penguasaan tehnik dasar dan kondisi fisik yang baik. Dalam permainan bola voli ada beberapa macam teknik dasar yaitu: service, passing, blok dan smash. Smash merupakan salah satu senjata ampuh yang sering digunakan oleh para atlet bola voli untuk melakukan sebuah serangan dan memperoleh sebuah nilai. $^{3}$

Salah cara untuk meningkatkan kemampuan atau keterampilan teknik dasar smash, maka diperlukan kemampuan fisik yang prima disertai dengan latihan yang cukup. Dalam melakukan gerakan smash terutama untuk mencapai hasil yang optimal diperlukan daya ledak lengan yang baik sehingga menghasilkan laju bola yang keras. Hal tersebut dipertegas oleh kaitannya dalam pelaksanaan smash, daya ledak otot tungkai memiliki peran untuk memberikan tenaga sewaktu lengan memukul bola yang sekeras-kerasnya. Dalam daya ledak otot lengan merupakan kondisi fisik yang tidak dapat dipisahkan dan merupakan penunjang utama gerakan yaitu kekuatan otot dan kecepatan otot untuk mengarahkan tenaga maksimal untuk mengatasi tahanan. Daya ledak otot tungkai merupakan salah satu faktor sangat penting dan harus diperhatikan dalam permainan bola voli, terutama pada saat melakukan pukulan, sehingga dengan memiliki daya ledak otot lengan yang baik, akan menghasilkan smash yang lebih baik pula. Sebaliknya apabila seorang atlet memiliki daya ledak otot lengan yang lemah, maka dapat menyebabkan pukulan tidak terlalu keras ${ }^{4}$.

\footnotetext{
${ }^{3}$ Wachyu Bakti Bachtiar (2019). Hubungan Antara Daya Ledak Otot Lengan Dengan Kemampuan Smash Bola Voli Pada Ekstrakurikuler. Jurnal Maenpo : Jurnal Pendidikan Jasmani kesehatan dan rekreasi. h.19

${ }^{4}$ Wachyu Bakti Bachtiar (2019) ). Hubungan Antara Daya Ledak Otot Lengan Dengan Kemampuan Smash (C) 2021, Jurnal Sportif. PJKR e-ISSN: 2775-9873
}

Dari uraian di atas dapat disimpulkan bahwa dibutuhkan latihan beban untuk menunjang keberhasilan dalam melakukan teknik dasar smash bola voli, latihan beban atau weight training merupakan latihan fisik dengan bantuan karet ban motor yang dimodifikasi sebagai beban, yang tujun utamanya untuk memberikan efek terhadap otot-otot rangka dan memberikan perubahan secara jelas, khususnya ditunjukan untuk meningkatkan kekuatan otot guna membantu kemajuan penampilan seseorang. Sesuai dengan batasan strengh yaitu kemampuan otot untuk membangkitkan tegangan terhadap suatu tahanan maka latihan-latihan yang cocok untuk mengmabngkan kekuatan adalah latihan-latihan (resistance exercise) diaman kita harus mengangkan mendorong atau menarik suatu beban.

Berdasarkan hasil praobservasi masih menemukan beberapa permasalahan dalam permainan bola voli pada siswa. Permasalahan tersebut diantaranya : 1) masih banyak siswa yang mengalami kesulitan dalam melakukan keterampilan smash. Hal ini dikarenakan bola yang digunakan bola voli standar, sehingga hasil kurang maksimal. Bola dianggap besar, berat, keras dan sering mengalami sakit pada tangan. 2) Sebesar $68 \%$ siswa belum memenuhi KKM pada materi keterampilan smash dalam permainan bola voli. 3) Adanya keterbatasan sarana dan prasarana dalam permainan bola voli seperti alat permainan bola voli yang minim secara kuantitas dan kurang secara kualitas.

Banyak ragam model latihan yang dapat diberikan untuk meningkatkan kemampuan power smash salah satunya dengan cara latihan beban. Latihan beban menggunakan karet ban yang di kaitkan ke tiang merupakan salah satu media penyampaian informasi kepada penerimanya dalam hal ini informasi menambah power yang benar. Latihan beban yang dimaksud dalam penelitian ini

Bola Voli Pada Ekstrakurikuler. Jurnal Maenpo : Jurnal Pendidikan Jasmani kesehatan dan rekreasi. h.19 PJKR JURNAL 
adalah latihan beban dengan karet ban mobil yang dikaitakn ke tiang. Latihan beban tersebut secara mekanik mampu mengembangkan kemampuan dalam melakukan power smash.

Atas latar belakang yang telah diuraikan tersebut, peneliti mengangkat permasalahan pengaruh alat modifikasi latihan beban menggunakan karet ban mobil yang di kaitkan ke tiang terhadap keterampilan power Smash dalam permainan bola voli. maka penulis tertarik melakukan penelitian dengan judul "Pengaruh Latihan Beban Terhadap Pukulan Smash Pada Permainan Bola Voli“"

\section{METODE}

\section{Studi literatur}

Desain penelitian yang digunakan mengacu pada desain penelitian Menurut Danial dan Warsiah Studi Literatur adalah merupakan penelitian yang dilakukan oleh peneliti dengan mengumpulkan sejumlah buku buku, majalah yang berkaitan dengan masalah dan tujuan penelitian. Teknik ini dilakukan dengan tujuan untuk mengungkapkan berbagai teori-teori yang relevan dengan permasalahan yang sedang dihadapi/diteliti sebagai bahan rujukan dalam pembahasan hasil penelitian.

\section{Teknik Pengumpulan Data}

Sumber data adalah segala sesuatu yang dapat memberikan informasi mengenai data. Data yang diperoleh dengan studi literatur (pustaka). Teknik ini di sebut juga dengan studi pustaka yaitu cara menelusuri keputakaan yang berisi tentang teori-teori dari karya ilmiah baik yang sudah diterbitkan atau belum diterbitkan berupa hard copy atau sof copy yang ada pada buku-buku (e-books), makalah, journal online.

A. Data primer

Dalam proses penelitian, peneliti menggunakan data primer Sugiyono, menjelaskan sumber data adalah sumber data yang langsung

(C) 2021, Jurnal Sportif. PJKR e-ISSN: 2775-9873 memberikan data kepada pengumpul data. Sumber data penelitian ini adalah jurnal dari buku Witono Hidayat Buku Pintar Bola Voli 2017.

B. Data sekunder

Selain data primer peneliti juga menggunakan data sekunder. Sugiyono, menerangkan sumber sekunder adalah sumber yang tidak langsung memberikan data kepada pengumpul, bisa lewat orang atau dokumen yang ditulis oleh orang lain. Dalam peneletian ini sumber sekunder berupa artikel, jurnal nasional dan internasional dan karya ilmiah yang berkaitan dengan objek material.

Pentingnya studi literatur karena datanya bersifat tetap, autentik, mudah ditemukan, dan dapat dipertanggung jawabkan karena data literature tersebut memiliki keabsahan dan telah melalui prosedur penelitian yang standart. Studili teratur, sebagai tenik dalam penelitian untuk memperoleh data digunakan karena:

1. Data yang diperoleh berbentuk teori-teori yang mendukung kegiatan penelitian.

2. Data yang diperoleh nanti digunakan untuk melakukan ferifikasi kualitas teori yang ditemukan dari hasil penelitian.

3. Autentik data dari studi literatur dapat dipertanggung jawabkan.

Teknik studi literatur ini bersumber pada buku, laporan penelitian, jurnal ilmiah, dan catatan lain, berusaha mencari sumber-sumber teori yang relevan sesuai dengan tema dan permasalahan penelitian yang telah ditetapkan sehingga penelitian yang dihasilkan sesuai dengan yang diharapkan.

\section{Teknik Analisis Data}

Teknik analisis data yang digunakan dalam penelitian ini adalah Studi Literatur, yaitu teknik yang dilakukan dengan cara 
menganalisis data dan menilai semua data yang relevan dan fakta yang diperoleh dari objek yang dipilih serta mengutip dari teori, abstrak, artikel, jurnal dan ketentuan yang berlaku umum kemudian dari hasil analisis ditarik kesimpulan yang mewakili masalah-masalah yang ada. Berdasarkan kesimpulan dijadikan saran-saran yang dianggap perlu bagi penelitian ini.

\section{HASIL DAN PEMBAHASAN}

\section{Hasil}

Tes awal dilaksanakan bertujuan untuk mengetahui data awal sebelum siswa diberikan latihan skipping bagi kelompok eksperimen. Data tes awal adalah data keterampilan smash dalam permainan bola voli sebelum diberikan latihan skipping yang diberikan pada putra kelas X SMA siswa Negeri 4 Palu bagi kelompok eksperimen. Pelaksanaan pengambilan data awal pada hari senin tanggal 4 februari 2013. Deskriptif data Kemampuan smash dalam permainan bola voli sebelum di berikan latihan skipping (Tes awal) Data tes awal hasil kemampuan smash tercantum dalam tabel 1.3 berikut:

\begin{tabular}{|c|c|c|}
\hline No & Nama Siswa & $\begin{array}{c}\text { Kemampuan } \\
\text { Smash }\end{array}$ \\
\hline 1 & Azwar & 11 \\
\hline 2 & Muhammad fahri & 9 \\
\hline 3 & Buhari & 11 \\
\hline 4 & Ramdani & 7 \\
\hline 5 & Fauzan & 9 \\
\hline 6 & Laode & 10 \\
\hline 7 & Rifaldi & 9 \\
\hline 8 & Muhhamad rizaldi & 8 \\
\hline 9 & Rian & 10 \\
\hline 10 & Aan & 9 \\
\hline 11 & Dedi & 8 \\
\hline 12 & Adi & 13 \\
\hline 13 & Fahmi akbar & 9 \\
\hline 14 & Rian hidayat & 10 \\
\hline 15 & Irfan aziz afandi & 8 \\
\hline 16 & R.wahyu & 11 \\
\hline 17 & Ahmad junaedi & 12 \\
\hline 18 & Akliyanto & 8 \\
\hline 19 & Muhammad Ilyas & 9 \\
\hline 20 & Muhammad azan & 9 \\
\hline
\end{tabular}

Tes akhir dilaksanakan bertujuan untuk mengetahui data akhir setelah siswa diberikan latihan skipping. Sesuai program latihan pada kelompok E-JTPEHR
Volume 1 Nomor 3 ISSN : 2337-4535

Kemal, Pengaruh Latihan Skipping Terhadap Kemampuan Smash Dalam Permainan Bola Voli Pada Siswa SMA Negeri 4 Palu 12 eksperimen. Proses pelaksanaan tes akhir sama dengan pelaksanaan tes awal dan tes akhir ini dilaksanakan setelah program latihan skipping selesai. Selanjutnya kemampuan smash dalam permainan bola voli (tes akhir). Data tes akhir kemampuan smash dalam permainan bola voli tercantum pada tabel.

\begin{tabular}{|c|c|c|}
\hline No & Nama Siswa & $\begin{array}{c}\text { Kemampuan } \\
\text { Smash }\end{array}$ \\
\hline 1 & Azwar & 17 \\
\hline 2 & Muhammad fahri & 14 \\
\hline 3 & Buhari & 19 \\
\hline 4 & Ramdani & 13 \\
\hline 5 & Fauzan & 13 \\
\hline 6 & Laode & 16 \\
\hline 7 & Rifaldi & 17 \\
\hline 8 & Muhhamad rizaldi & 15 \\
\hline 9 & Rian & 14 \\
\hline 10 & Aan & 14 \\
\hline 11 & Dedi & 22 \\
\hline 12 & Adi & 19 \\
\hline 13 & Fahmi akbar & 18 \\
\hline 14 & Rian hidayat & 16 \\
\hline 15 & Irfan aziz afandi & 17 \\
\hline 16 & R.wahyu & 19 \\
\hline 17 & Ahmad junaedi & 15 \\
\hline 18 & Akliyanto & 17 \\
\hline 19 & Muhammad Ilyas & 16 \\
\hline 20 & Muhammad azan & 15 \\
\hline
\end{tabular}

Tabel 1.5 selisi sebelum dan sesudah diberikan latihan skipping pada siswa putra kelas X SMA Negeri 4 Palu

\begin{tabular}{|c|c|c|c|c|c|}
\hline No & $\mathrm{X} 1$ & $\mathrm{X} 2$ & $\begin{array}{c}\mathrm{D} \\
(\mathrm{X} 2-\mathrm{X} 1)\end{array}$ & $\begin{array}{c}\mathrm{D} \\
(\mathrm{D}-\mathrm{MD})\end{array}$ & $\mathrm{d}^{2}$ \\
\hline 1 & 11 & 17 & 6 & $-0,9$ & 0,81 \\
\hline 2 & 9 & 14 & 5 & $-1,9$ & 3,61 \\
\hline 3 & 11 & 19 & 8 & 1,1 & 1,21 \\
\hline 4 & 7 & 13 & 6 & $-0,9$ & 0,81 \\
\hline 5 & 9 & 13 & 6 & $-0,9$ & 0,81 \\
\hline
\end{tabular}
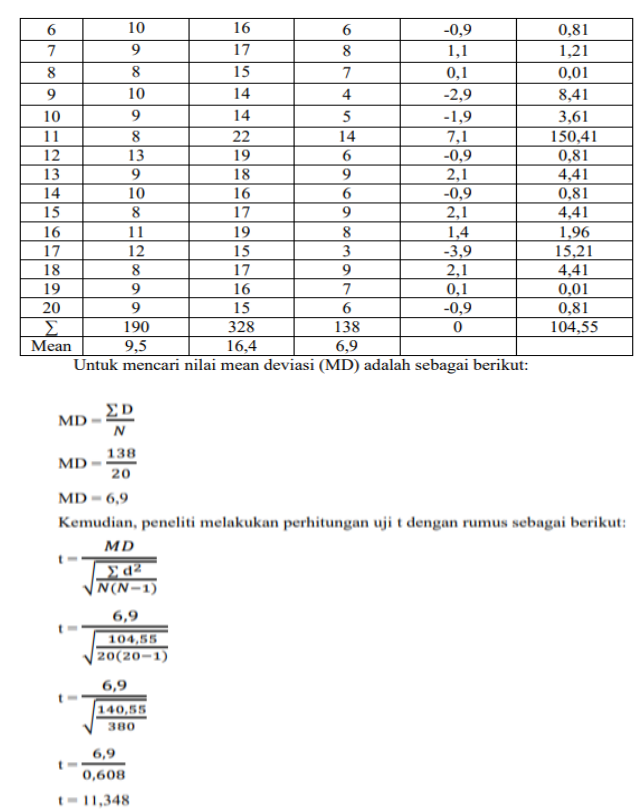


\section{Pembahasan}

Hasil perhitungan uji $\mathrm{t}$ dimana $\mathrm{t}$ hitung $=11,348$ diperoleh $\mathrm{t}$ tabel $=$ 2,093, karena $\mathrm{t}$ hitung lebih besar dari $\mathrm{t}$ tabel atau 11,348>2,093 pada taraf signifikan $5 \%$ dengan derajat perbedaan (d.b) $=20-1=19$, maka hipotesis nol (H0) yang menyatakan pengaruh tidak ada ditolak sehingga (hipotesis alternatif) diterima. Dengan demikian hipotesis menyatakan "Ada pengaruh yang signifikan latihan skipping terhadap kemampuan smash dalam permainan bola voli pada putra kelas X siswa Negeri Sma 4 Palu" diterima.

\section{PENUTUP}

\section{Kesimpulan}

Dari hasil analisis dan pembahasan hasil penelitian maka dapat ditarik kesimpulan sebagai berikut: Hasil analisis dan pembahasan hasil penelitian ini menunjukkan bahwa thitung $=11,348>$ ttabel $=2,093$, jadi thitung lebih besar dari ttabel sehingga $\mathrm{H0}$ dalam penelitian ini ditolak dan $\mathrm{H} 1$ diterima. Berdasarkan hasil tersebut maka hipotesis menyatakan ada pengaruh latihan skipping terhadap kemampuan smash dalam permainan bola voli pada putra kelas X siswa SMA Negeri 4 Palu. Agar hasil penelitian ini dapat dimanfaatkan pada arah yang positif serta untuk meningkatkan kedisiplinan atlet atau pemula, khususnya untuk meningkatkan prestasi bola voli, maka saran yang dapat dikemukakan sebagai berikut: 1. Karena penerapan latihan skipping mempunyai pengaruh yang bermanfaat terhadap kemampuan smash dalam permainan bola voli, maka disarankan kepada guru penjas atau Pelatih bola voli meberikan latihan tersebut pada program latihannya. 2 . Diharapkan sampel atau populasi dalam jumlah yang besar dan dapat divariasi dengan penelitian serupa.

\section{DAFTAR PUSTAKA}

Akhmad, Imran. (2013). Dasar-Dasar Melatih Fisik Bagi Olahragawan, Medan: UNIMED Press.

Anastasio Harimba (2017). Pengaruh latihan beban terhadap kadar kolesterol total darah. Skripsi.

Apta Mylsidayu, Febi Kurniawan. (2012) Ilmu Kepelatihan dasar. Bandung.

Aryadi Rachman (2017). Pengaruh latihan squat dan leg press terhadap strength dan hypertrophy otot tungkai. Jurnal olahraga.

Boby Agustan (2017). Perbandingan latihan kotak berwarna dengan segi tiga angka terhadap passing atas bola voli. Jurnal Olahraga.

Dr. Albertus Fenanlampir, M.Pd., AIFO. (2015). Tes \& pengukuran dalam olahraga. Cv. Andi offset (penerbit Andi).

Eko Sucipto (2016). Pengaruh latihan beban dan kekuatan otot terhadap hypertrophy otot dan ketebalan lemak. Jurnal Keolahragaan.

Fitra Harja Lugina (2020). Pengaruh Latihan Beban pada Lengan terhadap Ketepatan Servis Atas Peserta Ekstrakulikuler Bola Voli SMPN 3 Klari. Jurnal SPEED Volume 3 no 1 / Mei 2020 / ISSN 2621-6698.

H. Sunardi (2015). Bola voli. Hak cipta@ Sunardi \& Deddy Whinata Kardiyanto 2015. Hal. 40

Imam Cahyo Wahyu Wibowo. (2015) Skripsi. Yogyakarta. 
Kemal (2017). Pengaruh latihan skipping terhadap kemampuan smash dalam permainan bola voli pada siswa putra kelas $x$ siswa sma negeri 4 palu. E-jtpehr volume 1 nomor 3 issn : 2337-4535.

Kurniawan (2016). Pengaruh latihan plyometric terhadap hasil smash pada ekstrakurikuler bola voli. JUARA : Jurnal Olahraga.

lham Surya Fallo (2016). " upaya meningkatkan keterampilan smash permainan bola voli melalui pembelajaran gaya komando". Jurnal Pendidikan Olahraga. Kota pontianak.

Muhammad Riza Pranopik (2017). Pengembangan variasi latihan smash bola voli. Jurnal Prestasi.

Rice M. (2012) . pengembangan model latihan beban untuk meningkatkan kemampuan fisik pemain bola voli, tesis terdaulu yang relevan.

Sugiyono. (2012). Metode Penelitian Kuantitatif Kualitatif dan $R \& D$. Bandung: Elfabeta.

Sumbara hambali (2019). Keterampilan smash bola voli. Jurnal olimpia.

Wachyu Bakti Bachtiar 2019. Hubungan Antara Daya Ledak Otot Lengan Dengan Kemampuan Smash Bola Voli Pada Ekstrakurikuler. Jurnal Maenpo : Jurnal Pendidikan Jasmani kesehatan dan rekreasi. Universitas Suryakancana.

Witono Hidayat (2017). Buku pintar bola voli. Jakarta anugrah. Hal .46

Yanse Betna Arte(2019:). The Effect of Plyometric Exercise and Arm Muscle Strength on Smash Ability of Pervoba Volleyball Athletes. Journal of Physical Education and Sports. hal 138

(C) 2021, Jurnal Sportif. PJKR

e-ISSN: 2775-9873
Zabchi Noreddine (2016). The Effect of the Contrastive Training Using Weights and Plyometrics on the Development of the Vertical Jump Ability to Improve the Performance of the Smash for Volleyball Players. European Journal of Physical Education and Spo. 